\title{
PENERAPAN NAIVE BAYESIAN UNTUK PERANKINGAN KEGIATAN DI FAKULTAS TIK UNIVERSITAS SEMARANG
}

\author{
Astrid Novita Putri \\ Fakultas TIK \\ Universitas Semarang \\ Email: astrid@usm.ac.id
}

\begin{abstract}
ABSTRAK
Universitas Semarang adalah Salah satu perguruan tinggi swasta di Semarang, dengan jumlah mahasiswa aktif 12.000. Universitas Semarang mempunyai berbagai macam fakultas dan juga program studi di dalamnya. Di setiap program studi setiap tahun pasti selalu mengadakan kegiatan, entah kegiatan kemahasiswaan maupun kegiatan akademik. Salah satu kegiatan yang selalu di adakan setiap tahun adalah kegiatan Workshop, Kuliah Umum, Festifal, dsb. Dengan begitu banyaknya kegiatan yang sudah terlewati terkadang fakultas belum memberikan urutan dari mana sajakah program studi yang sering mengadakan kegiatan dan memiliki banyak peminat di dalam kegiatan tersebut. Oleh karena itu di perlukan suatu perankingan berdasarkan favorit dan tidak pada program studi manakah yang memiliki peminat sangat banyak, sehingga memacu program studi yang lain untuk giat membuat kegiatan yang menarik mahasiswa dan akan menambah pengetahuan baru bagi mahasiswa.Di Universitas Semarang memiliki beberapa fakultas dan program studi salah satunya adalah Fakultas Teknologi Informasi dan Komunikasi. Kemudian perankingan akan di buat menggunakan salah satu metode klasifikasi yaitu metode naive bayesian.
\end{abstract}

Kata Kunci: perankingan, naive, bayesian, kegiatan.

\begin{abstract}
Semarang University is one of the private universities in Semarang, with an active student population of 12,000. Semarang University has a variety of faculties and courses in it. In each course of study every year must always hold activities, whether student activities or academic activities. One of the activities that is always held every year is the workshop, Public Lecture, Festifal, etc .. With so many activities that have been missed sometimes the faculty has not given the order from which study programs are often held activities and have many enthusiasts in the activity. Therefore, in need of a ranking based on favorites and not on which study program has a lot of enthusiasts, thus spurring other study programs to actively create activities that attract students and will add new knowledge for students. At the University of Semarang has several faculties and programs one of which is the Faculty of Information and Communication Technology. Then the ranking will be made using one method of classification is naive bayesian method.
\end{abstract}

Keywords: ranking, naive, bayesian, activity.

\section{PENDAHULUAN}

Kegiatan adalah suatu aktivitas peristiwa atau kejadian pada umumnya yang di lakukan secara terus, pada universitas semarang memiliki beberapa fakultas dan program studi, setiap fakultas memiliki beberapa program studi, salah satunya adalah Fakultas Teknologi informasi dan komunikasi memiliki 3 program studi yaitu Teknik Informatika, Sistem Informasi dan Ilmu Komunikasi, di setiap program studi setiap tahun mengadakan suatu kegiatan, contohnya : Kuliah Umum, Seminar, Workshop, Festifal, dsb. Pada setiap kegiatan memiliki peserta baik dalam maupun dari luar Universitas Semarang, mahasiswa juga di wajibkan mengikuti kegiatan kegiatan yang ada di kampus, namun terkadang kegiatan pihak fakultas tidak memberikan klasifikasi pembeda manakah program studi yang memiliki banyak kegiatan dan memiliki jumlah peserta terbanyak. Oleh sebab itu di perlukan suatu klasifikasi pembeda, agar memacu program studi membuat kegiatan yang terbaru dan menambah pengetahuan untuk mahasiswa. Untuk mengklasifikasikan tersebut menggunakan metode pada artifical intelligent yaitu naive bayesian.

Metode naive bayesian adalah salah satu metode klasifikasi dan percabangan dari artifical intellegence, kegiatan-kegiatan tersebut akan di bentuk suatu Ranking yaitu Favorit dan Tidak Favorit, sehingga mahasiswa dan masyarakat dapat mengetahui kegiatan apa sajakah yang ada di fakultas TIK, 
dengan kriteria di bawah ini program studi, jenis kegiatan, hasil kegiatan, dan ranking. Dengan di latar belakangi tersebut peneliti akan membuat perhitungan klasifikasi program studi mana sajakah yang favorit dan tidak favorit.

\subsection{Data Mining}

Data mining yang di kenal dengan nama pattern recognition adalah metode pengolahan untuk menemukan suatu pola yang tersembunyi untuk dapat di olah menjadi pengetahuan dan ilmu pengetahuan baru dan informasi dari data dan hasil untuk keputusan di masa depan.

Data mining juga dapat di sebut sebagai sistem pengolahan data yang sangat besar, yang memberikan peranan dalam beberapa bidang di dunia yaitu bidang keuangan, industri, transportasi, cuaca, dan teknologi. Dalam data mining juga terdapat metode metode yang daat di gunakan anatra lain metode klasifikasi, clustering, regresi, seleksi variabel, dan market bisnis. Data mining dapat di artikan sebagai data dalam jumlah besar yang di simpan dalam suatu database, data warehouse untuk menyimpan dapat sehingga dapat menemukan pola. Ada beberapa teknik dalam data mining antara lain data analisis, signal proccesing, neural network dan pengenalan pola.

\subsection{Metode Klasifikasi Naive Bayesian}

Naïve Bayes adalah suatu metode klasifikasi dalam data mining dengan menggunakan metode probabilitas dan statistik sesuai dengan di kemukakan oleh ilmuwan inggris bernama Thomas Bayes. Kemudian Menurut Olson: 2008 : p 102 menjelaskan bahwa Nä̈ve Bayes merupakan suatu kelas keputusan, dengan menggunakan perhitingan probabilitas matematika dengan syarat bahwa nilai keputusan adalah benar, berdasarkan informasi obyek.

Sedangkan The Nä̈ve Bayesian classifier, atau Simple Bayesian Classifier menurut Han, Kamber $2011:$ p3 : 51 yaitu :

a) Variabel D merupakan suatu set tuple dan label yang berkait dengan kelas, kemudian setiap tuple mewakili vektor atribut $\mathrm{n}$ dan dimensi $\mathrm{X}=(\mathrm{x} 1, \mathrm{x} 2, \ldots, \mathrm{xn})$, yang menggambarkan pengukuran $\mathrm{n}$ pada tuple dari atribut $\mathrm{n}$, masing masing adalah $\mathrm{A} 1, \mathrm{~A} 2, \ldots, \mathrm{An}$.

b) Kelas $\mathrm{M}, \mathrm{C} 1, \mathrm{C} 2, . ., \mathrm{Cm}$. Di berikan suatu tuple $\mathrm{X}$, untuk klasifikasi prediksi X yang akan menjadi kelompok memiliki probabilitas posterior tertinggi, kondisi tersebut di sebutkan pada X. Artinya adalah sebagai berikut klasifikasi Nä̈ve Bayes memprediksi bahwa X tuple memiliki kelas Ci. Rumus dapat di sebutkan pada gambar di bawah ini.

$P(C i \mid X)>P(C j \mid X)$ For $1 \leq j \leq m, j \neq i$

Rumus Classifier Nä̈ve Bayesian

Sumber: Han, Kamber :2011: p351

Keterangan :

a. $\mathrm{P}(\mathrm{Ci} \mid \mathrm{X})=$ Probabilitas hipotesis Ci jika diberikan fakta atau record $\mathrm{X}$ (Posterior probability)

b. $\mathrm{P}(\mathrm{X} \mid \mathrm{Ci})=$ besar (likelihood)

c. $\mathrm{P}(\mathrm{Ci}) \quad$ Prior probability dari $\mathrm{X}$ (Prior probability)

d. $\mathrm{P}(\mathrm{X}) \quad$ Jumlah probability tuple yg muncul

\subsection{Kerangka Pemikiran}

Kerangka pemikiran merupakan garis besar dari langkah - langkah penelitian yang sedang dilakukan, kerangka pemikiran dijadikan acuan untuk melakukan tahap - tahap yang sedang dilakukan dalam penelitian. 
Permasalahan

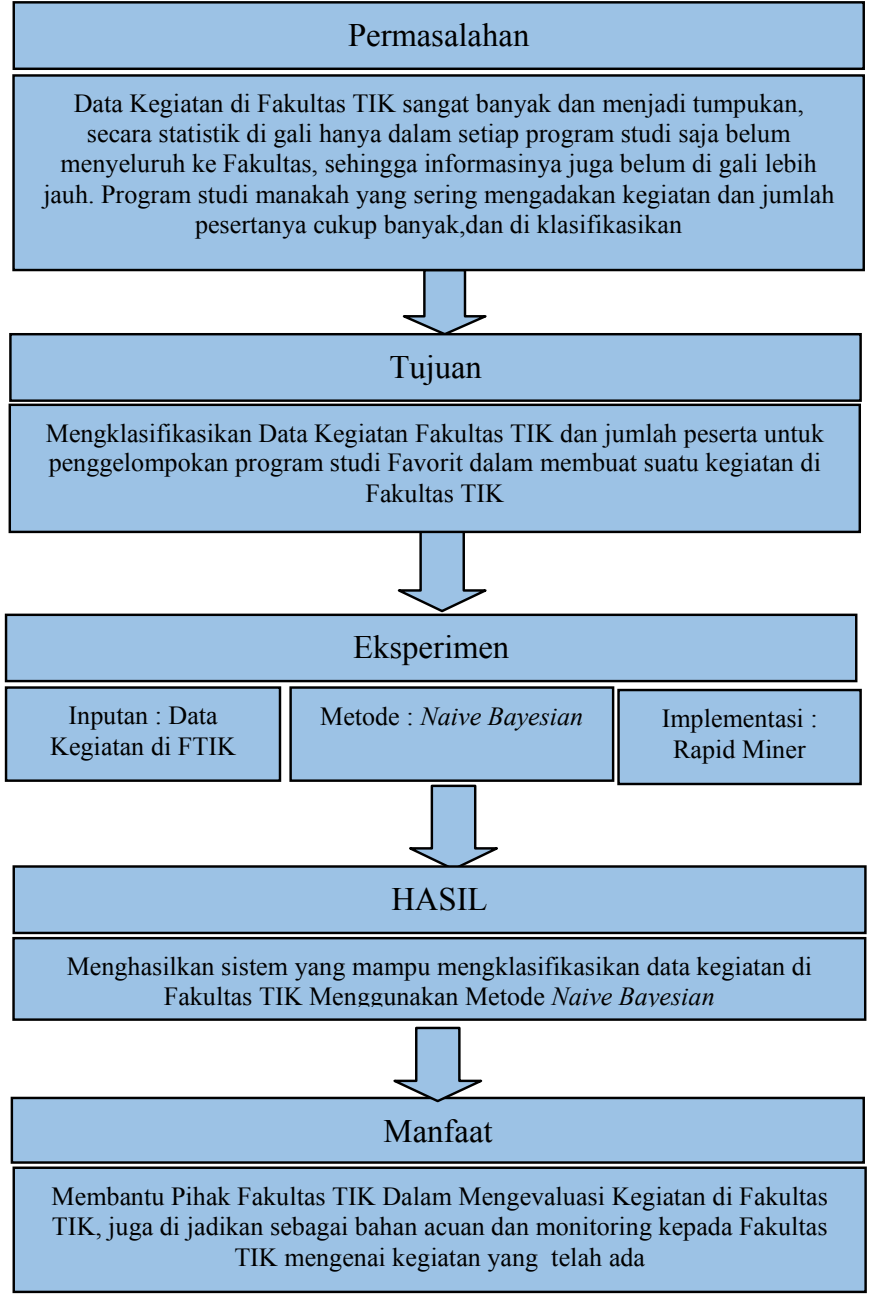

Gambar 1. Flow Chart Kerangka Pemikiran

\section{METODOLOGI PENELITIAN}

Pada bagian ini akan membahas mengenai jenis dana dan metode pengumpulan data yang di gunakan.

\subsection{Jenis Data}

Jenis data yang digunakan dalam penelitian ini yaitu:

a) Data primer, yaitu data yang diperoleh secara langsung dari objek penelitian, sebagai berikut : Kegiatan yang ada di fakultas TIK, Jumlah peserta, kemudian ranking yang akan di dapatkan.

b) Data sekunder, yaitu data yang diperoleh dari literature, buku referensi, maupun browsing internet.

\subsection{Metode Pengumpulan Data}

Metode pengumpulan data yang dilakukan dalam penelitian ini adalah:

a) Observasi dan Wawancara : Pengumpulan data melalui pengamatan dan wawancara secara langsung dengan Ketua Program Studi Teknik Informatika, Sistem Informasi, dan Ilmu Komunikasi mengenai kegiatan apa sajakah yang ada di dalamnya dan menganalisa kriteria yang di gunakan dari jenis kegiatan, tanggal kegiatan, hasil kegiatan, dan ranking yang di dapat dari hasil klasifikasi jumlah peserta.

b) Studi Pustaka : Mengumpulkan literatur pendukung penelitian, baik dari buku referensi ataupun browsing dari internet. 


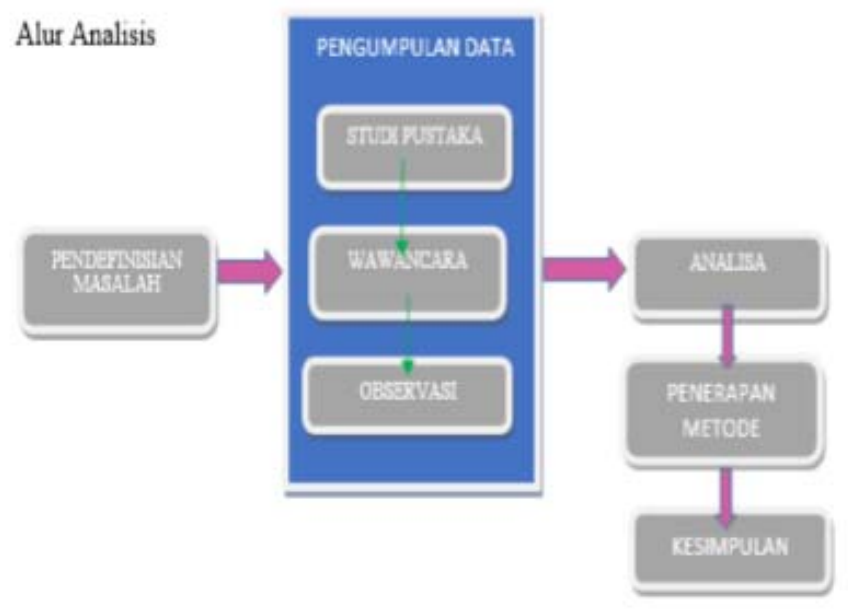

Gambar 2. Alur Analisis

Pada penelitian ini di awali dengan pendefinisian masalah hingga metode yang akan di gunakan. Di bawah ini adalah tahapan sebagai berikut:

a) Pendefinisian permasalahan berkaitan dengan merancang suatu analisa.

b) Studi Pustaka : Pengumpulan data yaitu berupa literatur buku, jurnal nasional maupun internasional, kemudian penelitian yang pernah di lakukan peneliti sebelumnya.

c) Wawancara : Melakukan proses wawancara tanya jawab dengan pihak ketua program studi Teknik Informatika, Sistem Informasi, dan Ilmu Komunikasi.

d) Observasi : Pengamatan langsung proses kegiatan yang ada

e) Analisa : Melakukan analisa pada hasil observasi, wawancara, penelitian sebelumnya.

f) Penerapan Metode : Metode mana sajakah yang akan di gunakan pada klasifikasi program studi mana sajakah yang favorit.

g) Pengambilan Kesimpulan Oleh Peneliti.

\section{HASIL DAN PEMBAHASAN}

\subsection{Penentuan Kriteria}

Berikut ini adalah kriteria dalam menentukan hasil berdasarkan ranking menggunakan metode klasifikasi : Naive Bayesian berikut ini :

a) Progdi : Teknik Informatika, Sistem Informasi, Ilmu Komunikasi.

b) Jenis Kegiatan : Kuliah Umum, Workshop, Pelatihan, Kegiatan Akademik, Kegiatan Ilmiah.

c) Hasil Kegiatan (Berdasarkan Peserta) : Memuaskan, Cukup (Di dapatkan dari jumlah peserta kegatan)

d) Ranking : Favorit, Tidak Favorit.

\subsection{Analisa Perhitungan Metode Naive Bayesian}

Berikut ini adalah tabel traning dari dataset kegiatan di Fakultas TIK Pada Tahun 2016 adalah di bawah ini ada 13 data terdiri dari 4 data kegiatan program studi Teknik Informatika, 3 kegiatan program studi Sistem Informasi dan 6 kegiatan pada program studi Ilmu Komunikasi.

Tabel 1. Traning kegiatan fakultas TIK Universitas Semarang

\begin{tabular}{ccccc}
\hline No & Program Studi & Jenis Kegiatan & Hasil Kegiatan & Ranking \\
\hline 1. & Teknik Informatika & Workshop Instal U-Buntu Realase & Memuaskan & Favorit \\
& & Party 11.04 & Memuaskan & Favorit \\
2. & Teknik Informatika & Workshop Framework PHP & Cukup & Tidak \\
3. & Teknik Informatika & Worshop Linux & & Favorit \\
& & & Memuaskan & Favorit \\
4. & Teknik Informatika & Workshop Sistem Sensor & Cukup & Tidak \\
5. & Sistem Informasi & Workshop Website & & \\
\hline
\end{tabular}




\begin{tabular}{|c|c|c|c|c|}
\hline No & Program Studi & Jenis Kegiatan & Hasil Kegiatan & Ranking \\
\hline 6. & Sistem Informasi & Festifal IT Fest & Memuaskan & $\begin{array}{l}\text { Favorit } \\
\text { Favorit }\end{array}$ \\
\hline 7. & $\begin{array}{c}\text { Sistem } \\
\text { Informasi }\end{array}$ & Workhsop Mikrotik & Cukup & $\begin{array}{c}\text { Tidak } \\
\text { Favorit }\end{array}$ \\
\hline 8. & Ilmu Komunikasi & Pelatihan Lab. TV & Cukup & $\begin{array}{c}\text { Tidak } \\
\text { Favorit }\end{array}$ \\
\hline 9. & Ilmu Komunikasi & Festival Charity & Cukup & $\begin{array}{c}\text { Tidak } \\
\text { Favorit }\end{array}$ \\
\hline $\begin{array}{l}10 . \\
11 . \\
12 .\end{array}$ & $\begin{array}{l}\text { Ilmu Komunikasi } \\
\text { Ilmu Komunikasi } \\
\text { Ilmu Komunikasi }\end{array}$ & $\begin{array}{c}\text { Festifal Komukino } \\
\text { Pelatihan Acara Retorika } \\
\text { Festifal Review TV }\end{array}$ & $\begin{array}{l}\text { Memuaskan } \\
\text { Memuaskan } \\
\text { Memuaskan }\end{array}$ & $\begin{array}{l}\text { Favorit } \\
\text { Favorit } \\
\text { Favorit }\end{array}$ \\
\hline 13 & Ilmu Komunikasi & Festifal Public Relation & Cukup & ??? \\
\hline
\end{tabular}

Kemudian Bagaimana Cara Menghitung No 13, Kategori Hasil Apakah Yang Akan di Dapatkan Dalam Hasil Ranking ?, Perhitungan Naive Bayesian :

a) Tahap 1 Menghitung jumlah class/label (Ranking)

$\mathrm{P}($ Favorit $)=7 / 12$

$\mathrm{P}($ Tidak Favorit $)=5 / 12$

b) Tahap 2 :

Menghitung Jumlah Untuk Masalah Sama dengan Class Yang Sama (Berdasarkan : Program Studi)

$\mathrm{P}(\mathrm{IK} \backslash$ Favorit $)=3 / 5$

$\mathrm{P}(\mathrm{IK} \backslash$ Tidak Favorit $)=2 / 5$

Menghitung Jumlah Untuk Masalah Sama dengan Class Yang Sama (Berdasarkan : Kegiatan)

$\mathrm{P}($ Festifal $\backslash$ Favorit $)=3 / 4$

$\mathrm{P}($ Festifal $\backslash$ Tidak Favorit $)=1 / 4$

Menghitung Jumlah Untuk Masalah Sama dengan Class Yang Sama (Berdasarkan : Hasil Kegiatan)

$\mathrm{P}($ Cukup $\backslash$ Favorit $)=0 / 5$

$\mathrm{P}($ Cukup $\backslash$ Tidak Favorit $)=5 / 5$

c) Tahap 3 Mengkalikan Semua Variabel Favorit dan Tidak Favorit

Klasifikasi Bayes Untuk Ranking : Favorit

$=\mathrm{P}($ Favorit $) . \mathrm{P}(\mathrm{IK} \backslash$ Favorit $) . \mathrm{P}($ Festifal $\backslash$ Favorit $) . \mathrm{P}($ Cukup $\backslash$ Favorit $)$

$=7 / 12 * 3 / 5 * 3 / 4 * 0 / 5$

$=0,58 * 0,6 * 0,75 * 0$

$=0$

Klasifikasi Bayes Untuk Ranking : Tidak Favorit

$=\mathrm{P}($ Tidak Favorit). $\mathrm{P}(\mathrm{IK} \backslash$ (Tidak Favorit). P(Festifal $\backslash$ (Tidak Favorit). P(Cukup $\backslash$ (Tidak Favorit)

$=5 / 12 * 2 / 15 * 1 / 4 * 5 / 5$

$=0,416 * 0,4 * 0,25 * 1$

$=0,0416$

Dari hasil perhitungan di atas, maka klasifikasi Bayes untuk Ranking dari record 13 yang di peroleh adalah "TIDAK FAVORIT" dengan nilai 0,0416 dibandingkan dengan kegiatan yang favorit.

\subsection{Implementasi Klasifikasi Naive Bayesian Pada Rapid Miner}

Berikut ini adalah pengolahan data dengan menggunakan naive bayesian pada Rapid Miner : 


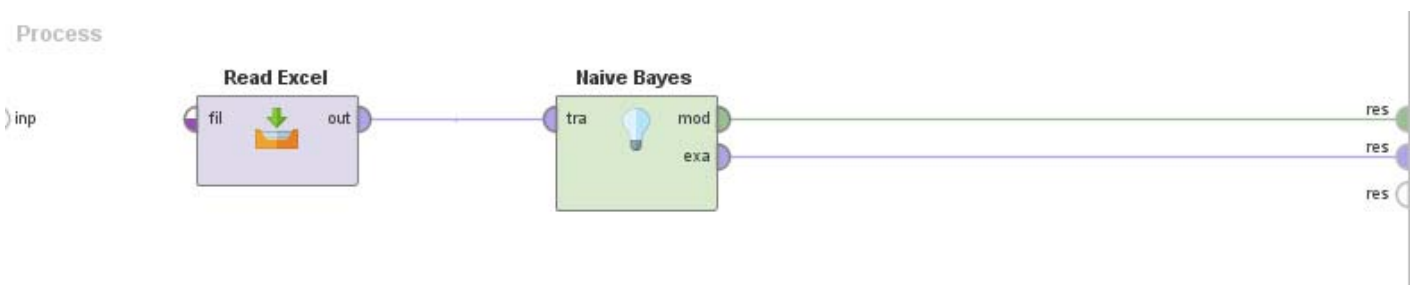

Gambar 3. Pemodelan Klasifikasi Naive Bayesian Pada Rapid Miner

Dengan menggunakn pemodelan klasifikasi naive bayesian seperti gamnar di atas dengan mengklasifikasi 2 jenis Favorit dan Tidak Favorit.Kemudian Berikut ini adalah hasil implementasi Kegiatan Curva Berdasarkan Favorit dan Tidak Favorit menggunakan RapidMiner menunjukkan kegiatan yang tidak favorit sangat tinggi di Fakultas TIK.

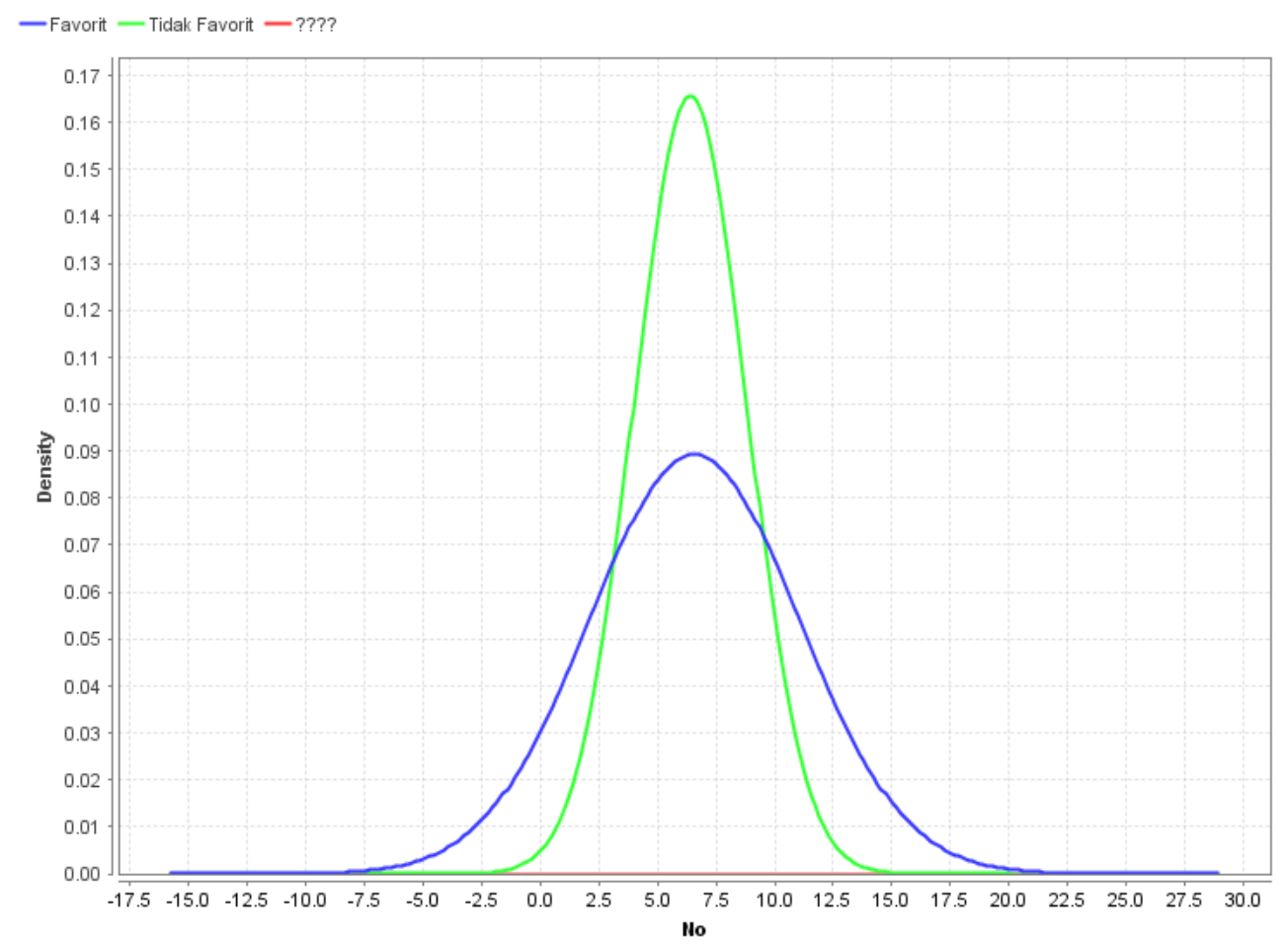

Gambar 4. Nilai Ranking Hasil Kegiatan Menggunakan Rapid Miner

Kemudian berdasarkan chart di Fakultas TIK pada hasil di bawah ini menunjukkan bahwa Program Studi Ilmu Komunikasi Menempati Urutan Terfavorit dengan Nilai 6, Menyusul urutan kedua yaitu Program Studi Teknik Informatika dengan nilai 4, dan urutan terakhir adalah Program Studi Sistem Informasi dengan nilai 3 pada Hasil Rapidminer. 


\begin{tabular}{l} 
Chart style: \\
Group-By Column: \\
Legend Column: \\
None \\
Value Column: \\
Ranking \\
$\square$ Absolute values \\
Aggregation: \\
\hline count \\
$\square$ Use Only Distinct \\
$\square$ Rotate labels \\
vertical \\
\hline
\end{tabular}

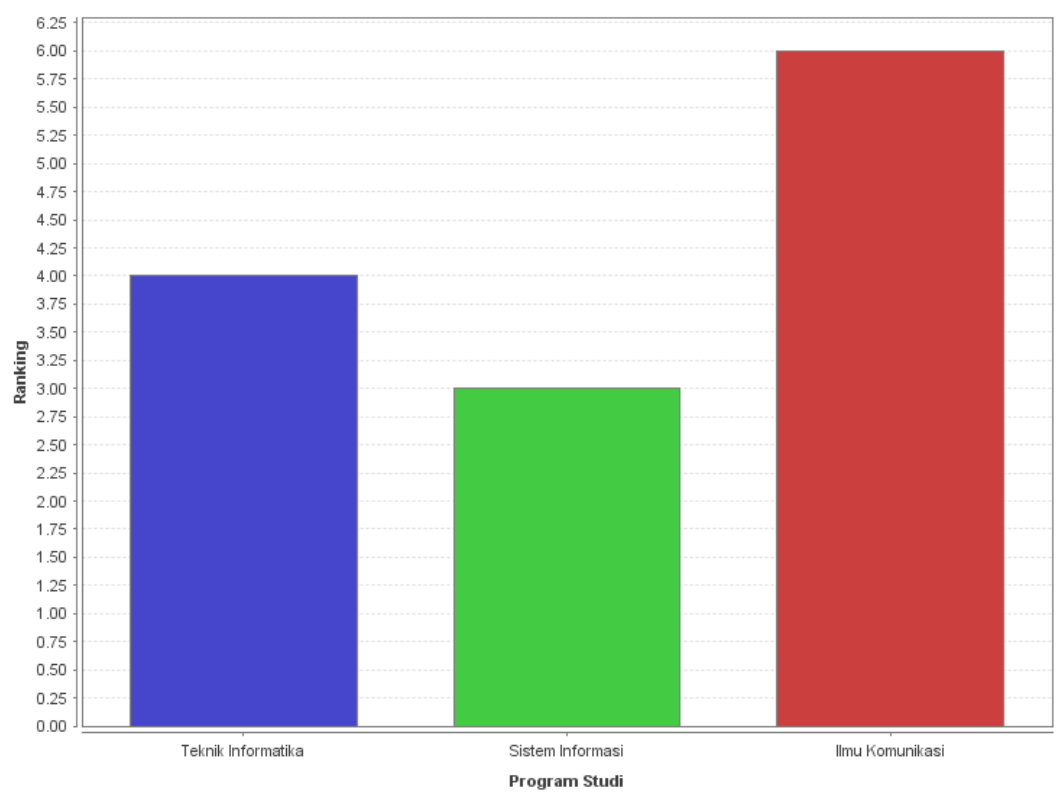

\section{Gambar 5. Chart Berdasarkan Program Studi}

\section{KESIMPULAN}

Dapat di simpulkan bahwa hasil perankingan pada Fakultas TIK Untuk kegiatan kegiatan yang telah ada masih menggunakan cara perhitungan manual dari hasil rata rata, klasifikasi menggunakan rata-rata hasil indikator data teknik statistik dasar, sehingga output yang di hasilkan kurang maksimal. Tumpukan data kegiatan di Fakultas TIK.

Berdasarkan data tahun 2017 menghasilkan klasifikasi menggunakan metode naive bayesian,dan program studi favorit adalah ilmu komunikasi berdasarkan hasil dari rapiminer. Untuk saran pada penelitian ini dapat di kembangkan dalam suatu aplikasi menggunakan bahasa pemrograman dan dapat di kembangkan dengan metode alghoritma klasifikasi yang lainnya.

\section{UCAPAN TERIMA KASIH}

Peneliti ucapkan terimakasih kepada pihak Dikti dan Universitas Semarang yang telah membiayai penelitian ini.

\section{DAFTAR PUSTAKA}

[1] Zhang, Harry, and Shengli Sheng. "Learning weighted naive Bayes with accurate ranking". ICDM 1-4 Nov 2004 : Fourth IEEE International Conference : 567-570 .

[2] Wagner, Daniel, et al. "Real-time detection and tracking for augmented reality on mobile phones". (2010). IEEE transactions on visualization and computer graphics : 355-368.

[3] Coiras, E., et al. "Supervised target detection and classification by training on augmented reality data". 2007 : IET Radar, Sonar \& Navigation 1.1. : 83-90.

[4] Silva, R., et al. "Object recognition using bayesian networks for augmented reality applications".2004 : VII Symposium on Virtual Reality.

[5] Arsyad, Azhar."Media Pembelajaran. cetakan ke-15”.Jakarta:Rajawalli Pers".2011

[6] Andi Prastowo.”Metode Penelitian Kualitatif dalam Perspektif Rancangan Penelitian”.2012

[7] J. O. Ong. "Implementasi Algoritma K-Means Clustering Untuk Menentukan Strategi Marketing President University”. 2013. Jurnal Ilmiah Teknik Industri, Vol. 12, no. 1, pp. : 10 - 20. 
Jurnal SIMETRIS, Vol 8 No 2 November 2017

ISSN: 2252-4983

[8] K. R. Prilianti dan H. Wijaya. "Aplikasi Text Mining Untuk Automasi Penentuan Tren Topik Skripsi Dengan Metode K-Means Clustering”. 2014. Jurnal Cybermatika,Vol. 2, no. 1, pp. 1-6. 